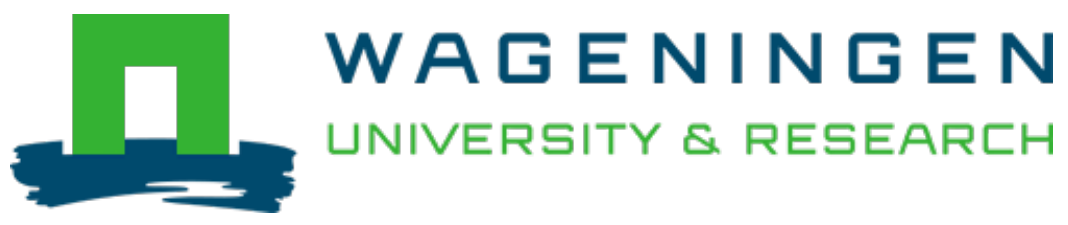

\title{
Microsatellite variation and population structure of a recovering tree frog (Hyla arborea L.) metapopulation
}

Conservation Genetics

Arens, P.F.P.; Bugter, R.J.F.; Westende, W.P.C.; Zollinger, R.; Stronks, J. et al

https://doi.org/10.1007/s10592-005-9112-7

This article is made publicly available in the institutional repository of Wageningen University and Research, under the terms of article $25 \mathrm{fa}$ of the Dutch Copyright Act, also known as the Amendment Taverne. This has been done with explicit consent by the author.

Article 25 fa states that the author of a short scientific work funded either wholly or partially by Dutch public funds is entitled to make that work publicly available for no consideration following a reasonable period of time after the work was first published, provided that clear reference is made to the source of the first publication of the work.

This publication is distributed under The Association of Universities in the Netherlands (VSNU) 'Article $25 \mathrm{fa}$ implementation' project. In this project research outputs of researchers employed by Dutch Universities that comply with the legal requirements of Article $25 \mathrm{fa}$ of the Dutch Copyright Act are distributed online and free of cost or other barriers in institutional repositories. Research outputs are distributed six months after their first online publication in the original published version and with proper attribution to the source of the original publication.

You are permitted to download and use the publication for personal purposes. All rights remain with the author(s) and / or copyright owner(s) of this work. Any use of the publication or parts of it other than authorised under article $25 \mathrm{fa}$ of the Dutch Copyright act is prohibited. Wageningen University \& Research and the author(s) of this publication shall not be held responsible or liable for any damages resulting from your (re)use of this publication.

For questions regarding the public availability of this article please contact openscience.library@wur.nl 


\title{
Microsatellite variation and population structure of a recovering Tree frog (Hyla arborea L.) metapopulation
}

\author{
Paul Arens ${ }^{1, *}$, Rob Bugter ${ }^{2}$, Wendy van't Westende ${ }^{1}$, Ronald Zollinger ${ }^{3}$, Jan Stronks ${ }^{4}$, \\ Claire C. $\operatorname{Vos}^{2}$ \& Marinus J. M. Smulders ${ }^{1}$ \\ ${ }^{1}$ Plant Research International, Wageningen University and Research Centre, P.O. Box 16, NL-6700 AA, \\ Wageningen, The Netherlands; ${ }^{2}$ Landscape Centre, Alterra, Wageningen University and Research Centre, \\ P.O. Box 47, NL-6700 AA, Wageningen, The Netherlands; ${ }^{3}$ RAVON, P.O. Box 1413, NL-6501 BK, \\ Nijmegen, The Netherlands; ${ }^{4}$ Staring Advies, Hummeloseweg 85, NL-7021 KN, Zelhem, The Netherlands \\ (*Corresponding author: Phone: +31-317476966; Fax: +31-317418094; E-mail: paul.arens@wur.nl)
}

Received 8 July 2005; accepted 29 December 2005

Key words: bottleneck, genetic diversity, habitat fragmentation, molecular marker, SSR

\begin{abstract}
Numbers and sizes of populations of the European tree frog in The Netherlands have dramatically decreased in the second half of the last century due to extensive habitat destruction and fragmentation. We have studied the genetic structure of a slowly recovering meta-population. Strong genetic differentiation, estimated at eight microsatellite loci, was found between clusters of populations $\left(F_{\text {st }}\right.$-values above 0.2$)$. Within clusters, consisting of ponds within a radius of about $5 \mathrm{~km}$, European tree frog populations were less differentiated $\left(F_{\mathrm{st}}<0.08\right)$ and exact tests showed that most of the ponds within clusters were not significantly differentiated. Although local population sizes have been increasing since 1989, and some new ponds have been colonised in the direct vicinity of ponds that have been populated continuously, little evidence for gene flow between clusters of ponds was found (only one exception). Furthermore, levels of genetic diversity were low compared to populations in comparable areas elsewhere in Europe. Therefore, a continuous conservation effort is needed to prevent any further loss of genetic diversity. The alleviation of important barriers to dispersal between the clusters should be given a high priority for the restoration of the meta-population as a whole.
\end{abstract}

\section{Introduction}

Successive worldwide counts of amphibian populations show, in general, a steady decline (Houlahan et al. 2000; Stuart et al. 2004). Probably one of the most important factors in industrialised regions has been habitat destruction, so that a large proportion of the aquatic and terrestrial habitat disappeared or became of marginal quality (Semlitsch 2000). This has led to increased fragmentation of habitat (Gibbs 1998) and amphibian populations have often become separated by intensively used agricultural landscapes and other barriers. Because of the increased landscape resistance to dispersal and the increased distances between populations due to the loss of breeding ponds, gene flow between populations is likely to be seriously reduced. Combined with lower population sizes, due to deteriorated habitat quality, amphibian populations may suffer from decreased levels of genetic diversity and subsequent increased expression of inbreeding depression, (e.g. due to higher probabilities of fixing deleterious mutations; Frankham 1995).

One of the amphibian species that is suffering severely from habitat loss and fragmentation in 
The Netherlands is the European Tree frog (Hyla arborea L.). $H$. arborea belongs to the family Hylidae which is one of the largest and widely distributed families of anurans, with 48 genera and over 800 species found throughout the Americas, Europe, northern Asia and Africa. The European tree frog inhabits almost all of Europe and it is the only native tree frog in The Netherlands. The north-western species range of the European tree frog runs through The Netherlands, limiting its distribution to the Eastern and Southern part of the country. European tree frogs are highly vagile species that have specific ecological requirements for their breeding ponds and land habitat. Possibly due to their life history traits and to the ecological restrictions on pond quality and land habitat, the species responded very quickly to the sharp decrease in habitat.

Whereas in the recent past the species was rather common in the Netherlands, around 1970 European tree frogs were threatened with extinction and could only be found in four relatively small and isolated areas (Stumpel and Hanekamp 1986; Zollinger 2004). For the European tree frogs occurring in one of these areas, in the western part of the country (Sealand Flanders), it was established that the species indeed suffered from habitat fragmentation. Species occurrence was correlated to the amount of terrestrial and aquatic habitat in the pond surroundings (Vos and Stumpel 1996). The probability of extinction of a local population depended on pond size and the amount of suitable terrestrial habitat in the pond surrounding, while the colonisation probability depended on the number of ponds in its vicinity (Vos et al. 2000). Capture-recapture data showed that European tree frogs can disperse for distances of 10$12 \mathrm{~km}$, although distances larger than $4 \mathrm{~km}$ are rare (Stumpel \& Hanekamp 1986; Fog 1993). It was also shown that European tree frogs have a high preference to disperse to already occupied ponds, ignoring unoccupied ponds at closer ranges due to social attraction (Vos et al. 2000). It is yet unclear across which distances a network of local populations is effectively connected by dispersal.

A second area where the European tree frog still occurs is the Achterhoek in the eastern part of the country, where the number of ponds with more than 20 calling males diminished to only 4 ponds around 1980 (Stronks 2000). From then on, a series of conservation activities has slowly improved conditions which led to increasing population sizes and the re-colonisation of other ponds, including some that were newly created or restored (Crombaghs and Lenders 2001).

In 1998 a survey was made of all potential breeding ponds in this area and samples were taken from 12 ponds where spawning was observed. These included the four ponds from which historical population data indicated a continuous presence and which are being considered as possible source populations of the surrounding ponds. The aim of the present study was to analyse the genetic variation within and among the populations in this area in order to:

1. Test whether the habitat fragmentation has had an effect on population differentiation as an estimate of isolation between populations.

2. Verify the source population for the newly occupied ponds.

3. Estimate the level of gene flow within and between clusters of ponds using an assignment test.

In addition, we discuss the effect of the bottleneck on genetic diversity by comparing the genetic diversity in this area with data from other study areas across Europe. These analyses were used to infer conservation priorities for the species in this area.

\section{Material \& methods}

\section{Sampling localities and microsatellite typing}

The study was conducted in the eastern part of the Netherlands (Figure 1) in the province of Gelderland (Achterhoek area). Sampling was carried out during the breeding season of 1998. In total, tail samples were collected from 175 tadpoles from 12 ponds divided over 5 clusters (Table 1). Observations by Stumpel and Hanekamp (1986) and Fog (1993) indicated that European tree frogs rarely migrate more than $4 \mathrm{~km}$ in agricultural landscapes, although migration over more than $10 \mathrm{~km}$ has been recorded occasionally. Therefore, we initially grouped the sampled ponds into five clusters based on geographic distances between ponds, as Andersen et al. (2004) had previously. We refer to the samples from one pond as a 'population', and to ponds within a $4-5 \mathrm{~km}$ radius 


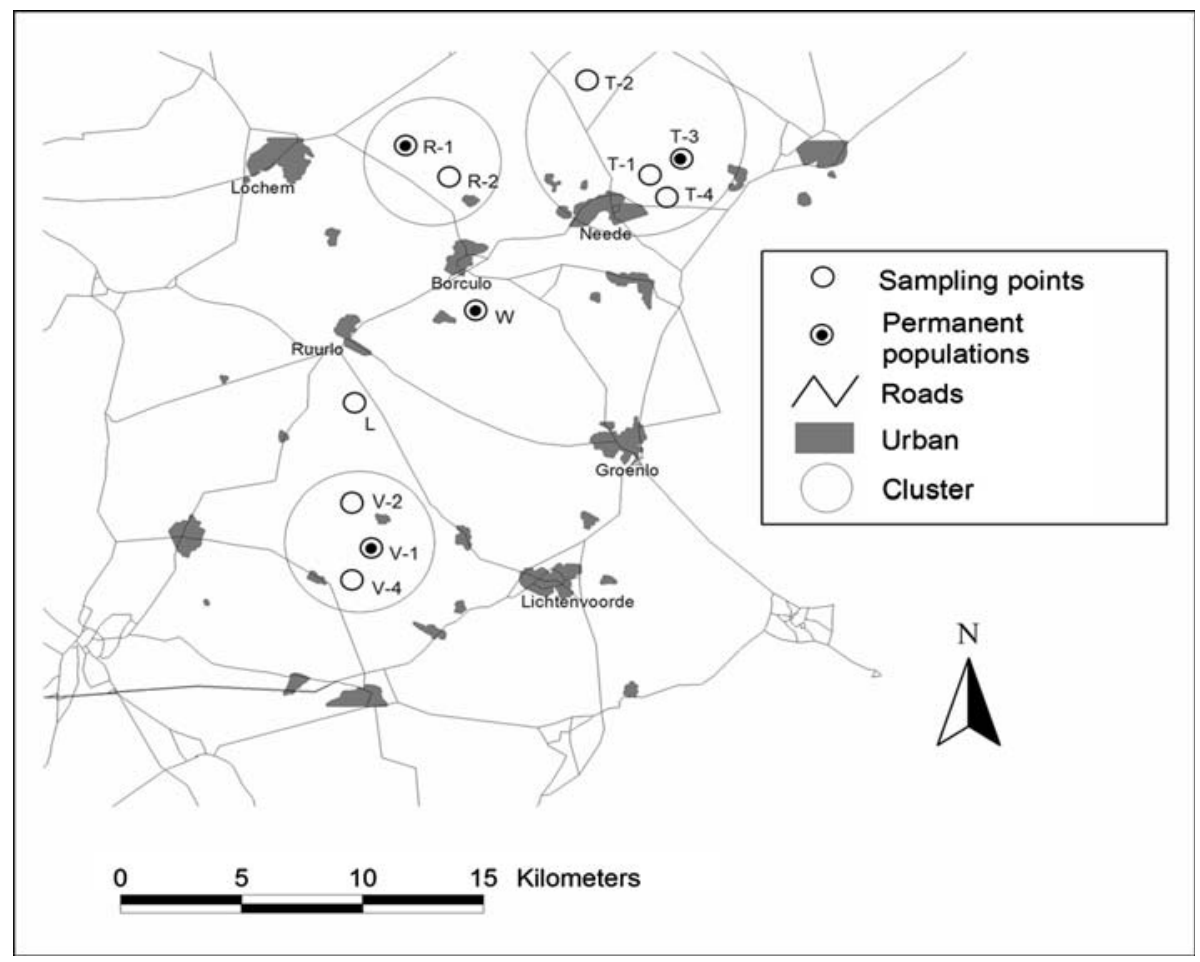

Figure 1. Study area showing distribution of ponds, roads and cities in the study area (pond T5, north between T1 and T3; not indicated).

Table 1. Levels of genetic variation and population sizes

\begin{tabular}{|c|c|c|c|c|c|c|c|c|}
\hline Cluster & Pond & Population & $H_{\mathrm{e}}$ mean & $F_{\text {is }}$ mean & $N_{\mathrm{em}}^{\mathrm{b}}$ & $\mathrm{M}$ ratio & $\mathrm{p}(\mathrm{M})$ & $N_{\text {sampled }}$ \\
\hline \multirow[t]{3}{*}{$\mathrm{R}$} & Roeterinksbroek* & $\mathrm{R} 1$ & 0.561 & -0.095 & 31.5 & 0.792 & 0.107 & 23 \\
\hline & Wanninkhof & R2 & 0.386 & -0.279 & 2.0 & 0.766 & 0.051 & 11 \\
\hline & Total & & 0.533 & & & & & \\
\hline \multirow[t]{6}{*}{$\mathrm{T}$} & Vleer & $\mathrm{T} 1$ & 0.536 & -0.160 & 7.33 & 0.649 & 0.003 & 8 \\
\hline & Brummelman & $\mathrm{T} 2$ & 0.546 & -0.270 & 10 & - & - & 9 \\
\hline & Oost Teeselinkven* & $\mathrm{T} 3$ & 0.570 & -0.107 & 26.7 & 0.713 & 0.016 & 13 \\
\hline & Kieftendijk & $\mathrm{T} 4$ & 0.576 & -0.080 & 5.9 & 0.667 & 0.004 & 17 \\
\hline & Needse Achterveld ${ }^{a}$ & T5 & - & - & - & - & - & 2 \\
\hline & Total & & 0.592 & & & & & \\
\hline \multirow[t]{4}{*}{$\mathrm{V}$} & Vildersveen* & V1 & 0.555 & -0.038 & 42.7 & 0.746 & 0.036 & 34 \\
\hline & Boerderij Maandag & $\mathrm{V} 2$ & 0.555 & 0.123 & 6.08 & 0.600 & 0.001 & 12 \\
\hline & Stuive zand & V4 & 0.581 & -0.088 & 8.12 & 0.688 & 0.007 & 10 \\
\hline & Total & & 0.577 & & & & & \\
\hline $\mathrm{W}$ & Waterster* & $\mathrm{W}$ & 0.438 & -0.145 & 26.22 & 0.628 & 0.002 & 22 \\
\hline $\mathrm{L}$ & Laarbraakweg & $\mathrm{L}$ & 0.515 & -0.090 & 6.06 & 0.682 & 0.008 & 14 \\
\hline
\end{tabular}

*Ponds that were already occupied in 1985 and which are suspected to have functioned as source populations.

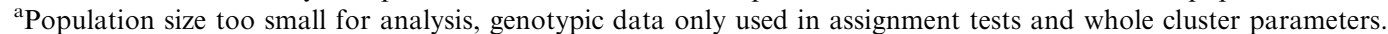

${ }^{\mathrm{b}}$ Harmonic mean of calling males for the populations from 1985 until 1997; for T2 only the estimated number of calling males in 1998 is given.

around possible source populations as a 'cluster' of populations. The distance between ponds varied from $1.2 \mathrm{~km}$ (T1 to $\mathrm{T} 4)$ to $24.1 \mathrm{~km}$ (T2 to V4).
Sample sizes ranged from 14 individuals in a single pond cluster to 56 individuals in a cluster consisting of 3 ponds. 
Population size of the European tree frog may vary across years. Grid surveys have indicated a severe decrease of $70 \%$ in European tree frog presence with the lowest numbers of occupied grids between 1970 and 1985. Estimates of the number of calling males $\left(N_{\mathrm{em}}\right)$ per pond, as an indication of population size, were available from 1985 onwards (Stronks 2000), except for the population in pond Brummelman (T2), which was counted only in 1998. The number of calling males, $N_{\mathrm{em}}$, used here is the harmonic mean of calling males from 1985 onwards.

DNA was extracted from samples using a standard phenol-chloroform protocol (Sambrook et al. 1989). Eight previously described microsatellite markers WHA5-22A, WHA5-201, WHA160, WHA1-104, WHA1-09, WHA1-20, WHA1-25 and WHA1-140 were used to genotype each individual (Arens et al. 2000). Genotyping was either done using silver staining detection as described by Arens et al. (2000) or using an ALF express DNA sequencer (Pharmacia; see Bredemeijer et al. 1998 for details).

\section{Data analysis}

Unless stated otherwise, analyses were performed using Fstat 2.93 (Goudet 1995). For analyses involving multiple comparisons the critical probability for each test was adjusted using the sequential Bonferroni correction (Rice 1989). Population genetic parameters were calculated for ponds and for the clusters of ponds. Genetic diversity was estimated as allelic richness (number of alleles per locus standardised to smallest number of individuals, El Mousadik and Petit (1996)) for each cluster, and as observed $\left(H_{\mathrm{O}}\right)$ and expected $\left(H_{\mathrm{E}}\right)$ heterozygosities within ponds. Evidence of linkage disequilibrium was assessed using Markov chain approximations (Guo and Thompson 1992). Similarly, deviations from Hardy-Weinberg equilibrium were tested in TFPGA (Miller 1997) for each locus and population separately.

The level of population differentiation was quantified using the $F_{\mathrm{ST}}$-estimator of Weir and Cockerham (1984). Similarly, $F_{\mathrm{SC}}$, the level of differentiation between populations within clusters, and $F_{\mathrm{CT}}$, the level of differentiation between clusters, were estimated. Significances of pairwise population differentiations were tested using the log-likelihood statistic G (Goudet et al. 1996). Partitioning of genetic diversity through AMOVA was performed using Arlequin (available from http://www.anthro.unige.ch/arlequin).

An estimate of the number of subpopulations represented in the samples was made using the program STRUCTURE (Pritchard et al. 2000), run without prior population information. This program uses a Markov chain Monte Carlo (MCMC) method that clusters individuals to minimise Hardy-Weinberg disequilibrium and linkage disequilibrium between loci. Runs were performed with a burn-in length of 10,000 and a MCMC of 100,000 and 5 runs were performed for each $\mathrm{K}$. The range of possible Ks tested was from 1 to 12 . The assignment results derived from STRUCTURE were compared with other assignment tests; Doh (Paetkau et al. 1995; program available at http://www.2.biology.ualberta.ca/jbrzusto/Doh.php) and Geneclass (version 2, Piry et al. 2004), as suggested by Pearse and Crandall (2004). Finally, a STRUCTURE model was used incorporating the assigned populations and using the USEPOPINFO option of the program. In this analysis the putative migrants were implemented as learning samples without prior population information to provide probabilities associated with these samples. Evidence of a recent population bottleneck was assessed for each population with BOTTLENECK (Cornuet and Luikart 1997) using the Wilcoxon signedrank test and the recommended TPM mutational model (variance 30 , probability $70 \%$ ). A qualitative descriptor of the allele frequency distribution (mode-shift indicator) was also used to detect evidence of bottlenecks (Luikart et al. 1998). Given the reduced sample sizes, the bottleneck analysis is supplemented with the "M ratio test" of Garza \& Williamson (2001). This method examines the mean ratio of the number of microsatellite alleles to the range in allele size, a fraction shown to be smaller in bottlenecked populations. Similarly to Andersen et al. (2004), the percentage one-step mutations was set to $80 \%$ whereas the average size of non-one-step mutations was the recommended 3.5.

A relationship between genetic differentiation and geographical distance among pairwise comparisons of populations was tested using Mantel's procedure with 5000 permutations of the data using Genstat (Payne et al. 1993). 


\section{Results}

All 8 microsatellite loci were polymorphic and the total number of alleles varied from 2 to 10 . Only one locus (WHA5-22) was monomorphic in one population (R2). Out of a total of 50 alleles detected across the loci, 8 were unique for 1 cluster, of which 5 were found in only 1 population. Expected heterozygosity values per population ranged from 0.386 in R2 to 0.581 in V4 (Table 1, only means over all loci are given). Surprisingly the overall $F_{\text {IS }}$ (within population inbreeding level) was negative and highly significant $\left(F_{\text {IS }}=-0.071\right.$; $99 \%$ C.I. -0.02 to -0.16 ) indicating a slight overall surplus of heterozygotes compared to expectations. Genetic diversity estimated as the allelic richness within clusters varied from 1.9 to 6.0 (Table 2).

A deviation from Hardy-Weinberg equilibrium, indicating a heterozygote deficiency, was observed in only 1 out of 88 tests at the single locus level (population W at locus WHA 1-25) after applying sequential Bonferroni corrections $(\alpha=5 \%)$.

Across all populations, pairwise $F_{\mathrm{ST}}$ levels ranged from no differentiation between two populations from one cluster T (T3 and T2) to as high as 0.36 between populations R2 and V4 (Table 3 ). Differentiation among the five clusters was strong $\left(F_{\mathrm{CT}}=0.18\right.$, see also Table 4$)$ with high divergence among pairs of clusters (pairwise $F_{\mathrm{CT}}$ levels ranging from 0.07 to 0.29 ). Levels of differentiation between populations within the same cluster were low $\left(F_{\mathrm{SC}}=0.04,2.9 \%\right.$ of the total variance;
Table 4). An exact test for population differentiation indicated that none of the populations within a cluster were significantly differentiated from each other, with the exception of populations R1 and R2 (Table 3). Furthermore, population L did not significantly differentiate from its nearest neighbour population $\mathrm{V} 2$ in cluster $\mathrm{V}$ (only $4.4 \mathrm{~km}$ apart), although this could be due to the small sample sizes from these two populations.

The number of subpopulations $(k)$ was estimated using STRUCTURE (Pritchard et al. 2000). The likelihoods obtained suggest that within the samples seven genetically distinct groups can be identified $(k=6, \mathrm{Ln}=-2917 ; k=7, \mathrm{Ln}=-2880$; $k=8, \mathrm{Ln}=-2902$; average result of multiple runs). The identified groups and the mean individual admixture proportions ( $q$ mean) are given in Table 5. For each individual the proportion of admixture to the different groups was estimated. Individual admixture proportions indicated that, individuals from clusters $\mathrm{R}$ and $\mathrm{W}$ each form a distinct group. Individuals from cluster $\mathrm{T}$ showed admixture between two groups indicating the presence of two groups whereas admixtures of individuals from the combined clusters $\mathrm{L}$ and $\mathrm{V}$ indicate three groups. For seven individuals the largest proportion of their admixed genotype assigned them to one of the other clusters (Table 5). This may indicate these individuals are possible migrants. Four of those individuals were also assigned to the same cluster by either Doh or Geneclass or both (marked separately in Table 5). In total for all 3 methods combined, 11 individuals were assigned outside their cluster of origin, of

Table 2. Allelic Richness per marker and per cluster (rarefaction for clusters $=14$ )

\begin{tabular}{|c|c|c|c|c|c|c|}
\hline \multirow[t]{2}{*}{ Marker } & \multicolumn{5}{|c|}{ Cluster } & \multirow[t]{2}{*}{ Total } \\
\hline & $\mathrm{R}$ & $\mathrm{T}$ & $\mathrm{V}$ & W & $\mathrm{L}$ & \\
\hline HA5-22 & 2.0 & 2.0 & 2.0 & 2.0 & 2.0 & 2.0 \\
\hline HA5-20 & 3.0 & 3.0 & 3.8 & 2.0 & 2.0 & 3.3 \\
\hline HA1-60 & 4.3 & 5.3 & 3.8 & 2.6 & 4.0 & 6.2 \\
\hline HA1-104 & 2.7 & 3.8 & 3.8 & 1.9 & 3.0 & 4.4 \\
\hline HA1-09 & 5.9 & 5.4 & 5.1 & 4.7 & 6.0 & 6.3 \\
\hline HA1-20 & 2.0 & 3.0 & 3.6 & 2.0 & 3.0 & 3.2 \\
\hline HA1-25 & 4.8 & 4.4 & 5.1 & 4.0 & 4.0 & 6.4 \\
\hline HA1-140 & 4.4 & 3.5 & 5.0 & 5.5 & 5.0 & 6.6 \\
\hline Private alleles ${ }^{\mathrm{a}}$ & 1 & 3 & $3^{\mathrm{b}}$ & 1 & $0^{\mathrm{b}}$ & 8 \\
\hline
\end{tabular}

${ }^{\mathrm{a}}$ Allele frequencies of private alleles range between 0.011 and 0.128 , mean 0.054 .

${ }^{\mathrm{b}} \mathrm{In}$ addition to the eight private alleles, one allele was found only in the clusters $\mathrm{V}$ and $\mathrm{L}$. 
Table 3. Pairwise $F_{\mathrm{ST}}$ values between populations and the significance of population differentiation (all significant unless indicated)

\begin{tabular}{|c|c|c|c|c|c|c|c|c|c|c|}
\hline & R1 & $\mathrm{R} 2$ & $\mathrm{~T} 1$ & $\mathrm{~T} 2$ & $\mathrm{~T} 3$ & $\mathrm{~T} 4$ & V1 & $\mathrm{V} 2$ & V4 & W \\
\hline $\mathrm{R} 2$ & 0.0748 & & & & & & & & & \\
\hline $\mathrm{T} 1$ & 0.2634 & 0.321 & & & & & & & & \\
\hline $\mathrm{T} 2$ & 0.2188 & 0.2719 & $0.0080^{*}$ & & & & & & & \\
\hline $\mathrm{T} 3$ & 0.2124 & 0.2607 & $0.0269^{*}$ & $-0.0063^{*}$ & & & & & & \\
\hline $\mathrm{T} 4$ & 0.1931 & 0.2202 & $0.0596^{*}$ & $0.0331^{*}$ & $0.0205^{*}$ & & & & & \\
\hline V1 & 0.2566 & 0.3108 & 0.0890 & 0.1839 & 0.1519 & 0.1416 & & & & \\
\hline $\mathrm{V} 2$ & 0.2447 & 0.3205 & 0.1127 & 0.2177 & 0.1812 & 0.1572 & $0.0172^{*}$ & & & \\
\hline V4 & 0.2478 & 0.3642 & 0.1429 & 0.2127 & 0.1899 & 0.1821 & $0.0284^{*}$ & $0.0137^{*}$ & & \\
\hline $\mathrm{W}$ & 0.2158 & 0.2806 & 0.3054 & 0.3080 & 0.2900 & 0.3034 & 0.2457 & 0.2450 & 0.2755 & \\
\hline $\mathrm{L}$ & 0.2693 & 0.3584 & 0.1218 & 0.2068 & 0.1667 & 0.159 & 0.0878 & $0.0527^{*}$ & 0.0906 & 0.2762 \\
\hline
\end{tabular}

${ }^{*}$ No significant population differentiation $(P=0.05)$.

Table 4. Nested Analysis of Molecular Variance (AMOVA) indicating partitioning of genetic diversity

\begin{tabular}{llccr}
\hline Source of variation & d.f. & Sum of squares & Variance components & Percentage of variance \\
\hline Among clusters & 4 & 160.631 & 0.52628 & 18.84 \\
Among populations within clusters & 7 & 28.819 & 0.08195 & 2.93 \\
Within populations & 338 & 738.685 & 2.18546 & 78.23 \\
\hline
\end{tabular}

Statistics include sums of squared deviations (SSDs), variance component estimates, the percentage of the total variance contributed by each component $(\%)$, and fixation indices at each level.

$*$ All indices are highly significant; the probability $(\mathrm{P})$ of obtaining a more extreme component estimate by chance alone $=<0.001$ (using 1000 randomisations).

which 6 were assigned by at least 2 of the 3 methods. Analysis, using STRUCTURE with the assigned populations as prior population information and the seven putative migrants from the initial STRUCTURE analyses as learning samples (see Pritchard et al. 2000 for details), showed very low admixture probabilities to any of the inferred populations.

Evidence for population bottlenecks was assessed using three methods. There was evidence for a 'mode-shift' in the allele frequency distribution (see Luikart et al. 1998) indicating a possible bottleneck in all populations, except for populations R1, T1, V1, W and L. For three of these populations (R1, V1, and $\mathrm{W}$ ) it was known that the ponds have been occupied for a very long time. These are also the populations that were suspected, by species specialists, to have functioned as source populations from which other ponds have been colonised. For population $\mathrm{L}$ this was uncertain. However, the results must be considered with caution as this method is qualitative (Luikart et al. 1998) and sample sizes were smaller than the 30 individuals recommended for the analysis. Putative bottlenecks were also assessed using the
Wilcoxon signed-rank test. Using this test a significant population bottleneck was observed in populations T2 and V4 after sequential Bonferroni correction $(\alpha=5 \%)$. Analysis using the "M ratio test" of Garza and Williamson (2001) showed that a significant population bottleneck (significant at $5 \%$ level after sequential Bonferroni procedure) may be observed in the six populations T1, T4, V2, $\mathrm{V} 4, \mathrm{~W}$, and $\mathrm{L}$, whereas this was not detected in the population R1, R2, T3 and V1 (see Table 1).

A significant correlation (Mantel's test, $P=$ 0.0195 ) was found between the pairwise genetic and geographic distances across all populations explaining as much as $34.5 \%$ of the total variation (Figure 2). The scatter plot shows that the level of population differentiation increases up to $15 \mathrm{~km}$, but at larger geographical distances (notably pairs of populations from the clusters $\mathrm{T}$ and $\mathrm{V}$ ) pairwise $F_{\mathrm{ST}}$ is relatively low.

\section{Discussion}

We studied a European tree frog population network which was recovering from a severe 


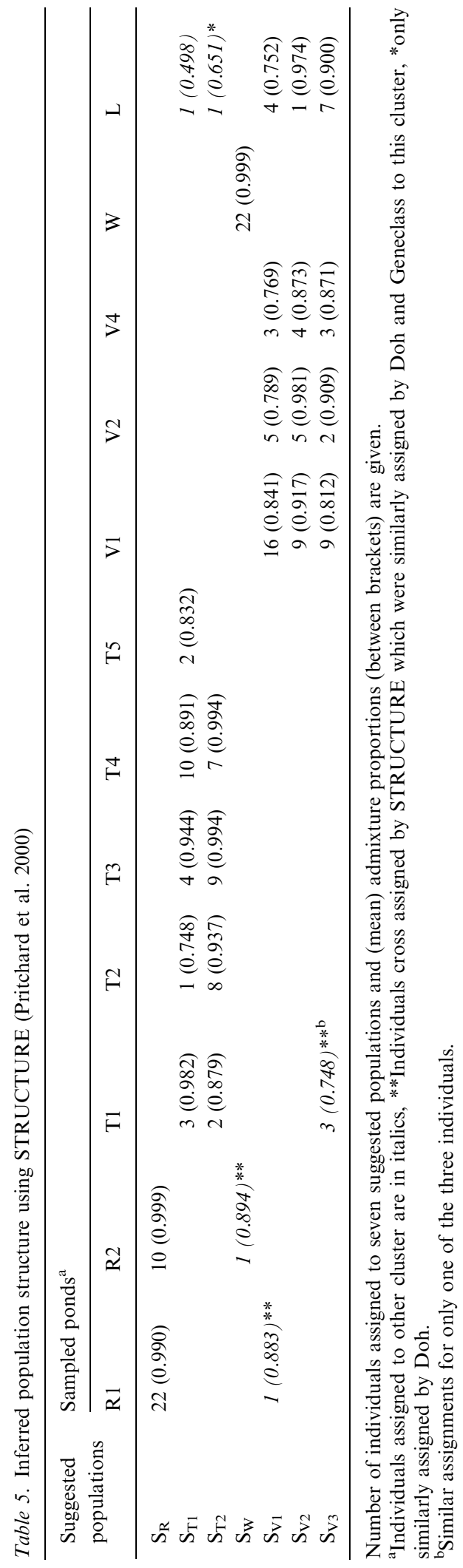

bottleneck, with the lowest population sizes in the years before 1985 when monitoring of the number of calling males per population started. Conservation measures to improve conditions for the European tree frog have been implemented in the study area by creating or restoring ponds and by restoring suitable terrestrial habitat. Suitable terrestrial habitats for the European tree frog are mainly, sun exposed forest edges, hedgerows and field margins, with a well developed herb layer (especially bramble). These types of landscape elements have also been used in creating corridors between habitats for dispersal. Restoration projects aimed at increasing both water and terrestrial habitat by creating or restoring clusters of three prime habitats (reproductions ponds of 1000$2000 \mathrm{~m}^{2}$ that are optimal for the demands of the European tree frog and at least $10 \%$ of optimal terrestrial habitat in the direct vicinity of ponds) in combination with at least five smaller habitats in an area of 100 ha. Population sizes within all ponds, as well as the number of occupied ponds, have increased slowly in the last 20 years. We compared samples taken from ponds thought to have been continuously occupied since 1985 (where the harmonic means of calling males were above 20) with ponds that were re-colonised after 1985. In some of the restored ponds a very small population may have gone undetected in the first years of monitoring, in which case they would classify as partly independently recovered. We studied the genetic structure across these populations to analyse their mutual relationships and assess which population acted as source populations for re-colonisation. Furthermore, we compared the gene diversity found in our study populations to those of other, less bottlenecked populations in Europe.

Sampled populations were grouped into five clusters based on geographic distances between ponds. This clustering was largely confirmed by the analysis of population differentiation although population L was not significantly differentiated from population V2, and population R2 was differentiated from R1. The level of population differentiation observed indicates that populations in the different clusters are considerably isolated from each other. Population differentiation was mainly due to differences in allele frequencies. Most private alleles were found in clusters $\mathrm{V}$ and $\mathrm{T}$, which in the period shortly after 1985 recovered 


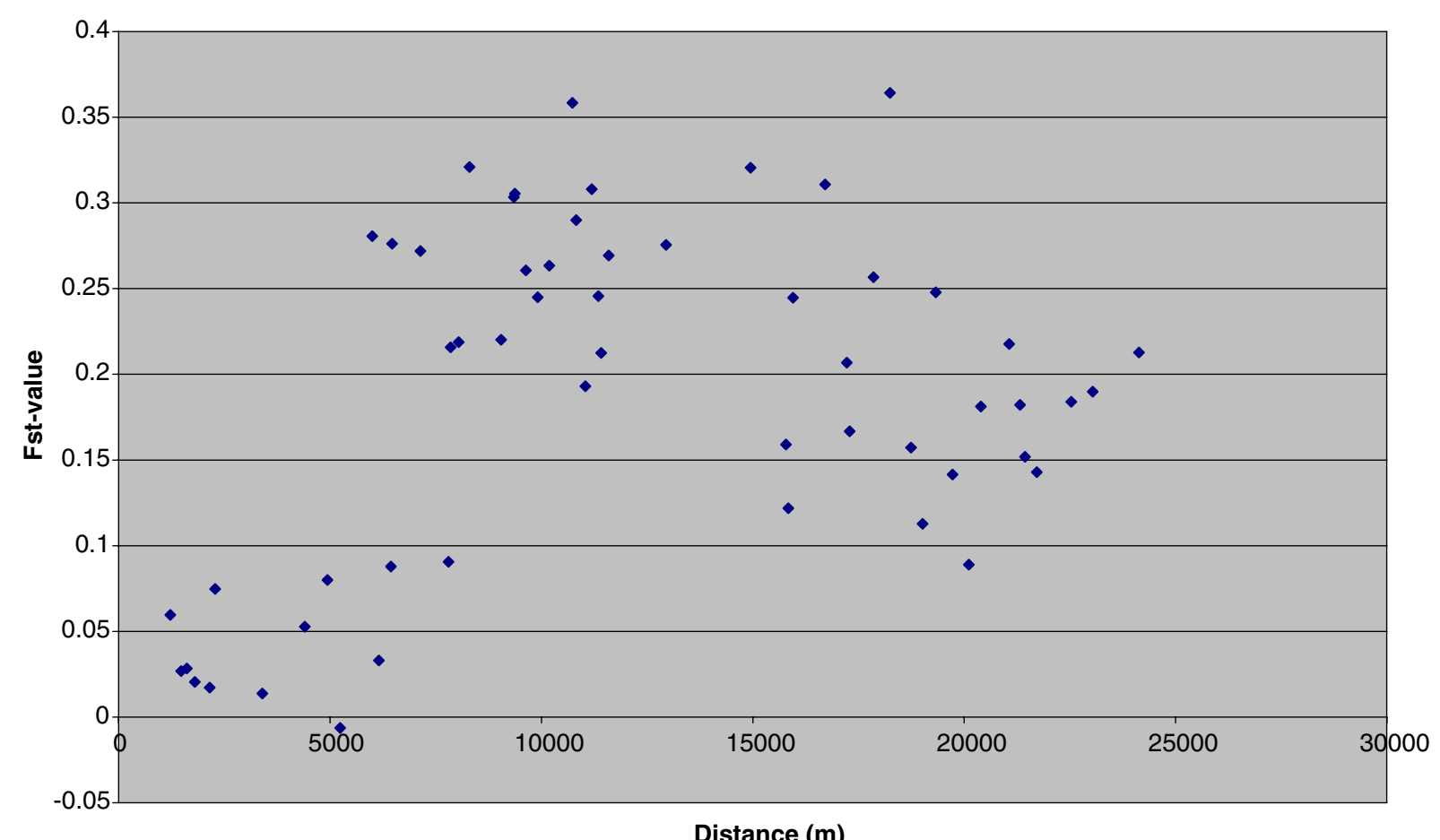

Figure 2. Scatter plot of pairwise genetic and physical distances.

much more quickly, and showed larger population sizes and numbers of occupied ponds compared to the other clusters. Our data suggest that these two clusters were able to retain more of their genetic diversity compared to the other clusters, and are consistent with the lower levels of population differentiation between populations of these two clusters.

Results from STRUCTURE indicated that ponds R1 and R2 belong to the same subpopulation. If this is correct, the significant differentiation between these two ponds in the exact test for population differentiation could be the result of a founder effect for R2. This is supported by the observation that alleles found in $\mathrm{R} 2$ are also the alleles with the highest frequencies in R1. Founder effects are also likely to have caused the modeshifts (Luikart et al., 1998) in allele frequencies observed in this and other populations that were (re)-colonised in the last 20 years, or that are suspected to have been restocked by one of the larger populations. It is at present unclear how the STRUCTURE program behaves in cases of high gene flow between populations (Pearse and Crandall 2004), but the suggested presence of two and three hypothetical populations within the clusters $\mathrm{T}$ and $\mathrm{V}$ (including $\mathrm{L}$ ), respectively, does not conflict with historical data on the number of ponds that were occupied in separate clusters from 1985 onwards. It could mean that the ponds do exchange individuals, but have remained genetically distinct.

Is this level of population differentiation normal for the European tree frog? The only comparable study of population structure in the European Tree frog (Andersen et al. 2004) produced similar $F_{\mathrm{ST}}$ values. However, since the range of distances between their ponds was almost twice that of our study (1.1-43.2 km versus $1.2-24.1 \mathrm{~km}$ here), the isolation between ponds in our landscape appears to be higher. The $F_{\mathrm{ST}}$ values we found are also high compared to other amphibian studies (see Newman and Squire 2001). The mean heterozygosity levels in our study area (0.39-0.59), except for populations $\mathrm{R} 2$ and $\mathrm{W}$, are slightly higher than those found by Andersen et al. (2004) for the Danish European tree frog populations (0.35-0.53) and by Newman and Squire (2001) for the common and widespread Rana sylvatica $(0.44$ 0.50 ), but lower than the formerly widespread 
Litoria aurea (Burns et al. 2004; 0.43-0.82) that has undergone a dramatic population decline during the last 30 years.

The "M ratio test" of Garza and Williamson (2001) may be the most suitable test for inferring population bottlenecks from our data, given the reduced sample sizes in a number of populations. Using this test, a significant population bottleneck was indicated in six populations, but not in three of the four populations (R1, T3, V1) for which the number of calling males in 1985 was above 20 and for which the $N_{\mathrm{em}}$ values showed the highest values, and not in R2 (the satellite population of R1). Although for the latter populations no bottleneck could be detected considerable genetic diversity may still have been lost in the past.

Allelic diversity may be more sensitive to bottlenecks and to the loss of genetic diversity compared to expected heterozygosity (Spencer et al. 2000). Arens et al. (2000) already noted the presence of markedly higher numbers of alleles in a few Croatian European tree frogs compared to a Dutch sample of European tree frogs. A comparison of the allelic diversity of populations in this study to those of European tree frog populations in Denmark, which have suffered much less fragmentation (L. Andersen, personal communication), and to populations in Switzerland, which also suffered less from fragmentation (S. Dubey, personal communication), was possible because seven of the 15 microsatellite loci described by Arens et al. (2000) were used in all three studies. Allelic diversity in the Swiss populations was higher ( $>0.3$ difference) than those of Dutch populations for four out of the seven markers, whereas in two markers the allelic diversity in the Dutch populations was higher. In the Danish European tree frog populations, conservation status was considered favourable when $N_{\mathrm{em}}>50$ and increasing or when $N_{\mathrm{em}}>500$ (Andersen et al. 2004). We compared our population data on allelic diversity to Danish samples from both bottlenecked and favourable populations. Allelic diversity estimated for the combined populations in our study area was lower than for the large, favourable Danish population at Barbrekaer $\left(N_{\mathrm{em}} \sim 500\right)$, but also lower for example, than the bottlenecked population at Agerholm $\left(N_{\mathrm{em}} \sim 7\right)$ in 5 out of the 7 microsatellite markers studied (total summed difference 7.7), even though the rarefaction used to calculate allelic richness in this comparison was higher in the Dutch population. The study of Andersen et al. (2004) showed a correlation between the level of genetic diversity in populations and fitness, measured as larvae survival in populations. The genetic diversity of populations in our study as a whole is comparable to those populations for which Andersen et al. (2004) found a decreased fitness and increased larval mortality. Therefore, fitness of the Dutch populations may also have been lowered. This raises concern for the long-term viability of the populations in our Dutch study area and warrants further research. At the very least, further loss of genetic diversity should be avoided.

Conservation measures over the last 20 years, aiming at improving pond quality, restoring terrestrial habitat and increasing pond densities, have resulted in a slow increase of the local population numbers and in re-colonisation of local populations. Colonisation of ponds in the periphery of the clusters has been observed (especially in the clusters $\mathrm{V}$ and $\mathrm{T}$ ), but the high differentiation between clusters found in this study indicates that dispersal between clusters is rare. Assignment tests showed some cross-assignments; these may indicate gene flow between clusters, but alternatively they may also be due to individuals having genotypes with common alleles, in which case there is no sign of dispersal among clusters of ponds. The latter possibility is supported by the low assignment probabilities for the putative migrants in the STRUCTURE analysis using the assigned populations as prior information and by the genetic isolation of population $\mathrm{W}$. This population has a crucial geographic position as a potential stepping stone between cluster V to the South and clusters $\mathrm{R}$ and $\mathrm{T}$ in the North, but its genetic distinction from all other clusters suggests no appreciable level of actual gene flow. Consequently, future conservation actions should focus on the improvement of connectivity between clusters, by restoring dispersal corridors and creating stepping stone habitats between the clusters. Enlarging the pond network to obtain a functional metapopulation connected by dispersing individuals across the clusters has several conservation advantages. A fully restored metapopulation would increase long-term survival probabilities of the European tree frog on a regional level (Etienne et al. 2004). Improving connectivity between clusters would also avoid further loss of genetic diversity by 
facilitating gene flow and may partly mitigate the possible (fitness-related) consequences of low genetic diversity in the local population clusters.

\section{Acknowledgements}

We kindly acknowledge private landowners and nature conservation organisations for their permission to access the ponds. L. Andersen is kindly acknowledged for sharing with us the information on allelic richness of Danish European tree frog populations.

S. Dubey is thanked for sending us DNA from two Swiss European tree frog populations and sharing information. We thank B. Vosman and W. van Delden for discussions and valuable comments on earlier versions of the manuscript. Three anonymous referees and $\mathrm{R}$. Hoelzel are thanked for their suggestions to improve the manuscript.

\section{References}

Andersen LW, Fog K, Damgaard C (2004) Habitat fragmentation causes bottlenecks and inbreeding in the European Tree frog (Hyla arborea). Proc. R. Soc. Lond. B. Biol Sci., 271, 1293-1302.

Arens P, Van't Westende W, Bugter R, Smulders MJM, Vosman B (2000) Microsatellite markers for the European Tree frog Hyla arborea. Mol. Ecol., 9, 1944-1946.

Bredemeijer GMM, Arens P, Wouters D, Vissser D, Vosman B (1998) The use of semi-automated fluorescent microsatellite analysis for tomato cultivar identification. Theor. Appl. Genet., 97, 584-590.

Burns EL, Eldridge MDB, Houlden BA (2004) Microsatellite variation and population structure in a declining Australian hylid Litoria aurea. Mol. Ecol., 13, 1745-1757.

Cornuet JM, Luikart G (1997) Description and power analysis of two tests for detecting recent population bottlenecks from allele frequency data. Genetics, 144, 2001-2014.

Crombaghs BHJM, Lenders HJR (2001) Conservation Plan Tree frog 2001-2005. Centre of Expertise, Ministry of Agriculture, Nature and Food Safety, Report nr. 42, Wageningen (In Dutch).

El Mousadik A, Petit RJ (1996) High level of genetic differentiation for allelic richness among populations of the argan tree (Argania spinosa L. Skeels) endemic to Morocco. Theor. Appl. Genet., 92, 832-839.

Etienne RS, Ter Braak CJF, Vos CC (2004) Application of stochastic patch occupancy models to real metapopulations. In: Ecology, Genetics, and Evolution of Metapopulations (eds. Hanski I, Gaggiotti OE), pp. 105-132. Elsevier Academic Press, New York.
Fog K (1993) Migration in the Tree frog Hyla arborea In: Ecology and conservation of the European Tree frog (eds. Stumpel AHP, Tester U), DLO Institute for Forestry and Nature Research, Wageningen.

Frankham R (1995) Inbreeding and extinction: Island populations. Conserv. Biol., 12, 665-675.

Garza JC, Williamson EG (2001) Detection of reduction in population size using data from microsatellite loci. Mol. Ecol., 10, 305-318.

Gibbs JP (1998) Distribution of woodland amphibians along a forest fragment gradient. Landscape Ecol., 13, 263-268.

Goudet J (1995) FSTAT (Version 1.2): A computer program to calculate F-statistics. J. Hered., 86, 485-486.

Goudet J, Raymond M, Demeeus T, Rousset F (1996) Testing differentiation in diploid populations. Genetics, 144, 19331940.

Guo SW, Thompson EA (1992) Performing the exact test of Hardy-Weinberg proportion for multiple alleles. Biometrics, 48, 361-372.

Houlahan JE, Findlay CS, Schmidt BR, Meyer AH, Kuzmin SL (2000) Quantitative evidence for global amphibian population declines. Nature, 404, 752-755.

Luikart GL, Allendorf FW, Cornuet JM, Sherwin WB (1998) Distortion of allele frequency distributions provides a test for recent population bottlenecks. J. Hered., 89, 238-247.

Miller MP (1997) Tools For Population Genetic Analyses 3.1 (TFPGA). A windows program for the analysis of allozyme and molecular population genetic data. Computer software distributed by author at http://www.bioweb.usu.edu/mpmbio/index.htm.

Newman RA, Squire T (2001) Microsatellite variation and finescale population structure of wood frogs (Rana sylvatica). Mol. Ecol., 10, 1087-1100.

Paetkau D, Calvert W, Sterling I, Strobeck C (1995) Microsatellite analysis of population structure in Canadian polar bears. Mol. Ecol., 4, 347-354.

Payne RW, Lane PW, Baird DB, Gilmour AR, Harding SA, Morgan GW, Murray DA, Thompson R, Todd AD, Tunnicliffe Wilson G, Webster R, Welham SJ (1993) Genstat 5, Release 3, Reference Manual, Clarendon Press, Oxford.

Pearce DE, Crandall KA (2004) Beyond $F_{\mathrm{ST}}$ : Analysis of population genetic data for conservation. Conserv. Genet., 5, 585-602.

Piry S, Alapetite A, Cornuet J-M, Paetkau D, Baudouin L, Estoup A (2004) GeneClass2: A software for genetic assignment and first-generation migrant detection. J. Hered., 95, 536-539.

Pritchard JK, Stephens M, Donnelly P (2000) Inference of population structure using multilocus genotype data. Genetics, 155, 945-959.

Rice WR (1989) Analyzing tables of statistical tests. Evolution, 43, 223-225.

Sambrook J, Fritsch EF, Maniatis T (1989) Molecular cloning: A laboratory manual, 2nd edn. Cold Spring Harbor Laboratory Press, New York.

Semlitsch RD (2000) Principles for management of aquaticbreeding amphibians. J. Wildl. Manag., 64, 615-631.

Spencer CC, Neigel JE, Leberg PL (2000) Experimental evaluation of the usefulness of microsatellite DNA for detecting demographic bottlenecks. Mol. Ecol., 9, 1517-1528. 
Stronks DJ (2000) Monitoring Boomkikker Achterhoek 2000, Staringadvies, Zelhem (In Dutch).

Stuart SN, Chanson JS, Cox NA, Young BE, Rodrigues ASL, Fischman DL, Waller RW (2004) Status and trends of amphibian declines and extinctions worldwide. Science, $\mathbf{3 0 6}$, 1783-1786

Stumpel AHP, Hanekamp G (1986) Habitat ecology of Hyla arborea in The Netherlands. In: Studies in Herpetology, Proceedings of 3rd meeting of S. E. H., Prague 1985 (ed. Rocek Z), pp. 409-411. Charles University, Prague.

Vos CC, Stumpel AHP (1996) Comparison of habitat-isolation parameters in relation to fragmented distribution patterns in the Tree frog (Hyla arborea). Landscape ecol., 11, 203-214.

Vos CC, Ter Braak CJF, Nieuwenhuizen W (2000) Incidence function modeling and conservation of the tree frog Hyla arborea in the Netherlands. Ecol. Bull., 48, 165-180.

Weir BS, Cockerham CC (1984) Estimating F-Statistics for the analysis of population structure. Evolution, 38, 13581370.

Zollinger R (2004) Das artenschutzprogramm laubfrosch in den Niederlanden. Zeitschrift für Feldherpetologie, Supplement, 5, 175-181. 